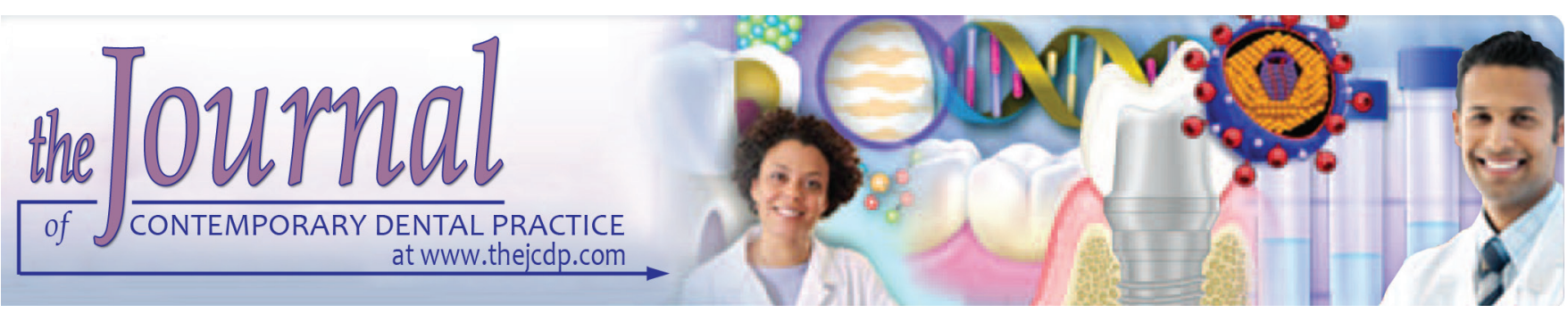

\title{
Apical Periodontitis and Endodontic Treatment in Patients with Type II Diabetes Mellitus: Comparative Cross-sectional Survey
}

Leena Smadi

\begin{abstract}
Aims: The aims of this study were to investigate the prevalence of apical periodontitis (AP) in diabetes mellitus (DM) patients compared with nondiabetic patients and to examine the effect of glycemic control on the prevalence of AP.

Materials and methods: Radiographs of a group of DM patients were compared with those of a matched nondiabetic group to identify AP. The diabetic group was subdivided according to the level of glycemic control into two subgroups: A well-controlled $\mathrm{DM}$ and a poorly controlled DM. The periapical index score was used to assess the periapical status. All groups were compared in regard to the presence of AP lesions, the number of endodontically treated teeth (ET), and the percentage of failure of endodontically treated teeth (AP/ET ratio). Statistical Package for the Social Sciences (SPSS version 20.0, Chicago, Illinois, USA) was used for all the analyses; $p \leq 0.05$ was considered as statistically significant.
\end{abstract}

Results: The prevalence of AP was higher in diabetic group than in the nondiabetic group (13.5 vs $11.9 \%$ respectively). Diabetic group had more teeth with endodontic treatment ET compared with nondiabetic group (4.18 vs $1.82 \%$ respectively); this difference was statistically significant $(p=0.001)$ along with higher AP/ET ratio (27.7 vs 19.3 respectively). The poorly controlled DM group had a higher prevalence of AP lesions compared with the well-controlled DM group (18.29 vs 9.21 respectively). This difference was statistically significant $(p=0.001)$; they also had a higher percentage of ET (5.55 vs $3.13 \%$ respectively) and AP/ ET ratio (32.0 vs $21.8 \%$ respectively).

Conclusion: This survey demonstrates a higher prevalence of AP in DM patients compared with nondiabetic group, with an increased prevalence of persistent chronic AP. Compared with a well-controlled diabetic group, a poor glycemic control may be associated with a higher prevalence of AP and increased rate of endodontic failures.

Department of Conservative Dentistry, University of Jordan Amman, Jordan

Corresponding Author: Leena Smadi, Department of Conservative Dentistry, University of Jordan, Amman, Jordan e-mail: alsomadi@yahoo.com
Clinical significance: Counseling diabetic patients, particularly those with poor glycemic control, about the risk of failure of endodontic treatment can be part of planning management, which could include refereeing diabetic patients who need endodontic treatment for consultant care.

Keywords: Apical periodontitis, Cross-sectional survey, Diabetes mellitus, Endodontic treatment, Glycemic control.

How to cite this article: Smadi L. Apical Periodontitis and Endodontic Treatment in Patients with Type II Diabetes Mellitus: Comparative Cross-sectional Survey. J Contemp Dent Pract 2017;18(5):358-362.

\section{Source of support: Nil}

\section{Conflict of interest: None}

\section{INTRODUCTION}

Diabetes mellitus (DM) is a chronic, complex disease that involves numerous pathophysiological features. ${ }^{1}$ It is one of the most prevalent diseases in the adult population. Persistent hyperglycemia is responsible for various types of organ and tissue damage in diabetic patients that results in long-term, systemic, debilitating complications. ${ }^{2}$ The relationship between oral health and diabetes has been investigated widely, especially its association with periodontal disease and dental caries. ${ }^{3-7}$

A wide range of chemical and physical factors can induce periradicular inflammation; scientific evidence clearly indicates that apical periodontitis (AP) infections are very prevalent and are caused by microbial factors, which may lead to the progression and perpetuation of different forms and are quite similar to those that cause periodontal disease. ${ }^{8}$ However, the literature on the relationship between DM and endodontic diseases is limited in all areas, including the pathophysiology, prevalence, and effect on treatment.

Pulp from patients with DM has a tendency to present with limited dental collateral circulation, an impaired 
immune response, an increased risk of acquiring a pulp infection (especially anaerobic ones) or necrosis, toothache, and an occasional tendency for pulp necrosis caused by ischemia. ${ }^{9}$

Few studies have suggested that DM may serve as a disease modifier of AP in that individuals with diabetes may be more prone to develop the primary disease. However, findings have not yet confirmed that diabetes may influence the response to root canal treatment because treated teeth had no increased prevalence of AP when compared with controls. ${ }^{10}$ Few studies have examined the effect of glycemic control on the prevalence of AP. ${ }^{11}$

The aims of this study were to investigate the prevalence of AP in diabetic patients compared with matched nondiabetic patients and to examine the effect of glycemic control on the incidence of AP.

\section{MATERIALS AND METHODS}

The study was performed in cooperation between an endocrinology clinic and consulting Endodontic Clinic at the King Hussein Medical Centre in Amman, Jordan, over a 6-month period (April 2015-September 2015). The study was approved by the Ethics Committee of our hospital, and written informed consent was provided by each participant after an informed consultation session was carried out by one of the residents working in the clinic.

\section{Sample Recruitment Process}

Out of 248 patients interviewed in the endocrine clinic, 142 diabetics agreed to participate in the study, in addition to 3 patients who had been diagnosed with DM from the control group. Therefore, 145 patients were enrolled in group I. At the Family Medicine Clinic, 461 patients were interviewed and invited to participate in the study; 149 agreed, but 3 of them were found to have undiagnosed DM. Thus, 146 nondiabetic patients were
Table 1: Demographic and background characteristics of the diabetic and control groups ( $\%$ and means)

\begin{tabular}{|c|c|c|c|}
\hline Characteristics & $\begin{array}{l}\text { Group I } \\
(n=145)\end{array}$ & $\begin{array}{l}\text { Group II } \\
(n=146)\end{array}$ & $p$-value \\
\hline \multicolumn{4}{|l|}{ Gender } \\
\hline Male & 48.96 & 51.37 & 0.821 \\
\hline Female & 51.04 & 48.63 & \\
\hline Mean $\pm S D$ & $49.6 \pm 8.85$ & $51 \pm 8.97$ & $0.325^{\dagger}$ \\
\hline \multicolumn{4}{|l|}{ Income (in $J O D^{\ddagger}$ ) } \\
\hline $0-200$ & 26 & 24 & 0.638 \\
\hline $201-400$ & 38 & 36 & \\
\hline $401-600$ & 29 & 31 & \\
\hline$>600$ & 7 & 9 & \\
\hline \multicolumn{4}{|l|}{ Educational status } \\
\hline Primary & 29 & 23 & 0.271 \\
\hline High & 27 & 31 & \\
\hline College & 22 & 21 & \\
\hline University & 22 & 25 & \\
\hline $\begin{array}{l}\text { Mean years since the } \\
\text { last visit to a dentist }\end{array}$ & $5.6 \pm 6.12$ & $5.2 \pm 6.54$ & $0.835^{\dagger}$ \\
\hline \multicolumn{4}{|l|}{ Smoking status } \\
\hline No & 73 & 69 & 0.683 \\
\hline Yes & 27 & 31 & \\
\hline \multicolumn{4}{|l|}{ Hypertension } \\
\hline No & 67 & 82 & 0.047 \\
\hline Yes & 33 & 18 & \\
\hline Body mass index & $26.19 \pm 3.92$ & $25.57 \pm 4.40$ & $0.384^{\dagger}$ \\
\hline
\end{tabular}

enrolled in group II. Groups I and II (control group) were matched for age, gender, income, education, presence of hypertension, body mass index (BMI), smoking, and the number of years that had elapsed since the patient's last visit to a dentist (Table 1).

Group I was subdivided into two groups; group III included 82 well-controlled DM (glycated hemoglobin $[\mathrm{HbA} 1 \mathrm{c}]<7 \%$ ), while group IV contained 63 patients with poorly controlled DM $(\mathrm{HbA} 1 \mathrm{c}>7 \%){ }_{i}^{12}$ the recruitment process is illustrated in Flow Chart 1.

Flow Chart 1: Recruitment process

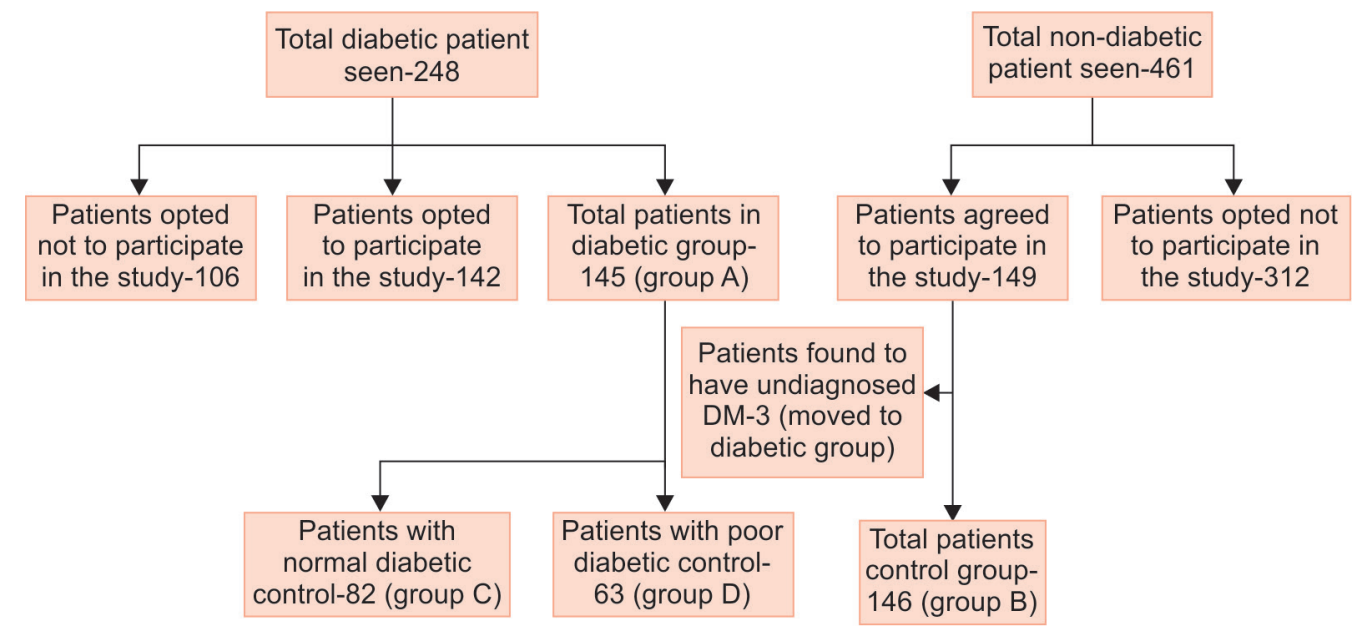




\section{Assessment of Periapical Status}

All participants were offered digital panoramic radiographs in the Endodontic Department. Two senior endodontists independently evaluated these anonymous panoramic radiographs. In cases of disagreement, a combined assessment session was held to reach a consensus. The two observers were previously calibrated, and the kappa coefficient was used to analyze the agreement regarding the presence/absence of a periradicular lesion $(\kappa=0.91)$. The periapical index (PAI) score was used to assess the periapical status. ${ }^{13} \mathrm{APAI} \geq 3$ was considered to be a sign of AP. In multirooted teeth, the worst score of all roots was taken to represent the PAI score for the teeth.

\section{Statistical Analysis}

The Statistical Package for the Social Sciences (SPSS, version 20.0, Chicago, Illinois, USA) was used for all the analyses. Adescriptive analysis was performed for sociodemographic features, health-related behaviors, radiographic data, the presence of diabetes, and diabetes control status. The normality of the distribution of continuous variables was tested using the graphic method. We performed a bivariate analysis to compare the presence of a periradicular lesion with several of the studied variables using the Mann-Whitney U-test for continuous data and the chisquared test or Fisher's exact test for categorical data. The threshold of statistical significance was set at $5 \%(p \leq 0.05)$.

\section{RESULTS}

\section{Diabetic Group I vs Nondiabetic Group II}

Diabetics showed a higher number of teeth with $\mathrm{AP}$, although this difference was not statistically significant. Diabetic group had more endodontically treated teeth (ET) compared with nondiabetic group (4.18 vs 1.82\% respectively); this difference was statistically significant $(\mathrm{p}=0.001)$ along with higher AP/ET ratio (27.7 vs 19.3 respectively) (Table 2 ).

\section{Well-controlled DM (Group III) vs Poorly Controlled DM (Group IV)}

Poorly controlled diabetic group had more AP lesions compared with the well-controlled diabetics (18.29 vs 9.21

Table 2: Periapical lesions (AP), ET, and the ratio of teeth with AP in ET in diabetic patients (group I) and nondiabetic controls (group II)

\begin{tabular}{llll}
\hline & $\begin{array}{l}\text { Group I, } \\
n=145(\%)\end{array}$ & $\begin{array}{l}\text { Group II, } \\
n=146(\%)\end{array}$ & $p$-value \\
\hline Number of teeth & 3111 & 3127 & $\mathrm{NS}$ \\
Teeth with AP & $409(13.15)$ & $372(11.90)$ & $\mathrm{NS}$ \\
Teeth with ET & $130(4.18)$ & $57(1.82)$ & $0.001^{*}$ \\
Teeth with AP/ET & $36(27.7)$ & $11(19.3)$ & 0.02 \\
\hline
\end{tabular}

*Statistical significance; NS: Not significant respectively). This difference was statistically significant ( $p=0.001)$; poorly controlled DM group also had a higher percentage of ET ( 5.55 vs $3.13 \%$ respectively) and the AP / ET ratio (32.0 us $21.8 \%$ respectively) (Table 3 ).

\section{DISCUSSION}

Diabetes mellitus is a common metabolic disease with an estimated prevalence of $17.1 \% .{ }^{1}$ Diabetes is associated with several factors that can cause the following complications: (1) Shunting through the polyol pathway, (2) enhanced oxidative stress, (3) high levels of protein kinase $C$ activation, and (4) enhanced formation of advanced glycation end products. Abnormalities in each of these pathways may affect a number of important cellular and molecular events, which can lead to pathologic changes when combined. ${ }^{14,15}$ Despite the high prevalence of DM and the extensive investigations and research on its impact on health of affected individuals that have taken place, few studies have evaluated the possible relationship between DM and endodontic infections. ${ }^{16-21}$

Our study was, therefore, designed to examine the prevalence of endodontic lesions in diabetic patients compared with controlled nondiabetic patients and also to investigate the effect of glycemic control on the progression of the endodontic disease.

The results of our study showed that compared with the control group, AP was more prevalent in diabetic patients regardless of whether their disease was controlled or uncontrolled (13.15 vs 11.9 respectively), although this difference did not reach statistical difference. The prevalence of AP in both groups (diabetics and controls) was higher than the incidence of AP reported in other studies in a general population from other countries. ${ }^{22-24}$ On the contrary, the AP prevalence in our control group was comparable to that reported by a Jordanian population study by Al-Omari et $\mathrm{al}^{25}$ (11.9 vs $11.6 \%$ respectively). This difference in the AP prevalence between a Jordanian population and other studies could be explained by the fact that the oral status of Jordanian adults is unsatisfactory in general due to poor oral hygiene, which causes a high incidence of carious teeth, and an overall unsatisfactory quality of fixed dentures. ${ }^{26}$ Socioeconomic status may also affect the quality of oral

Table 3: Periapical lesions (AP), ET, and ratio of teeth with AP in ET in patients with well-controlled diabetes (group III) and in poorly controlled diabetics (group IV)

\begin{tabular}{llll}
\hline & Group III, & Group IV, & \\
& $n=82(\%)$ & $n=63(\%)$ & $p$-value \\
\hline Number of teeth & 1759 & 1352 & NS \\
Teeth with AP & $162(9.21)$ & $247(18.29)$ & $0.001^{*}$ \\
Teeth with ET & $55(3.13)$ & $75(5.55)$ & 0.03 \\
Teeth with AP/ET & $12(21.8)$ & $24(32.0)$ & 0.02 \\
\hline
\end{tabular}

*Statistical significance; NS: Not significant 
hygiene. Our group of patients was mainly from a low socioeconomic background, a population where oral health is not always a priority.

The difference in AP between diabetic and nondiabetic patients has been demonstrated in a few studies that showed a higher prevalence of AP in diabetic patients. ${ }^{27-29}$

When controlled diabetic patients were compared with the noncontrolled group, the prevalence of AP was greater than that in the noncontrolled group (18.29 vs $9.21 \%$ respectively). This revealed the effect of poor diabetic control on the development of endodontic disease; this consequence of poor control of diabetes was also demonstrated by Sánchez-Domínguez et al, ${ }^{11}$ who demonstrated the relationship between glycemic control and periapical disease. Compared with our study, their results revealed a higher prevalence of $\mathrm{AP}$, both in controlled diabetics and noncontrolled diabetics. Other studies have reported a greater prevalence of AP lesions in diabetic patients compared with nondiabetic populations; ${ }^{10,30}$ these studies included smaller numbers than our study, and one of them was a retrospective study.

The percentage of ET was 2.3\%, which is low compared with the results of some other studies, ${ }^{22,31-33}$ in which the range was from 6.8 to $18.5 \%$. This could be a consequence of the survey population being unrepresentative of the whole country and/or due to differences in socioeconomic factors and the provision of dental care services in these various other countries. In contrast, our data were in agreement with a number of previous studies that found the prevalence of teeth that received ET to range between 1.3 and $4.8 \% .^{23,34-36}$

The effect of diabetes on the success of ET was demonstrated by the difference in the AP/ET percentages between diabetic and nondiabetic patients (27.7 vs 19.3\% respectively). Poor control of diabetes complicates the case more with more lesions in the noncontrolled diabetic group compared with controlled diabetic group (32 vs $21.8 \%$ respectively). This negative effect of diabetes on the success of ET can be explained by the results of many published studies, which have highlighted that glucose levels may interfere with the repair process of periapical changes; patients with diabetes who undergo dental procedures (particularly endodontic treatment) showed a poorer ability for wound repair. ${ }^{16,20,21}$ Animal studies have indicated that diabetics are more likely to be afflicted with extensive periradicular changes, which may be due to a reduction in their defense capacity against microbial agents. ${ }^{37}$ This lowered defense suggests the need for an adequate follow-up in these patients both before and following radicular ET, as many authors have suggested, ${ }^{38,39}$ particularly since the majority of these patients $(>50 \%)$ tend not to attend their followup visits. ${ }^{40}$
This study was a cross-sectional design that had some limitations. The data lacked a longitudinal follow-up and were also drawn from a small sample size that does not represent the entire diabetic adult population. However, the chance of researcher bias in our study was reduced compared with a longitudinal study because we used a cross-sectional design. Other limitations of our study included using radiographs as the only mode of diagnosis with increasing probability of incomplete diagnosis. In some cases, periradicular lesions are restricted to cancellous bone, which makes them undetectable on conventional radiographic examination ${ }^{41}$ in addition to the fact that periradicular diagnoses are influenced by the quality of the root filling. ${ }^{42}$

\section{CONCLUSION}

This study suggests a higher prevalence of AP in DM patients and increased number of ET. The prognosis for root-filled teeth was worse in diabetics, showing a higher rate of root canal treatment failure with an increased prevalence of persistent chronic AP. High level of $\mathrm{HbA} 1 \mathrm{c}$ $>7 \%$ is associated with higher prevalence of AP, increased number of ET as well as poorer prognosis of endodontic treatment evident by increased AP/ET ratio. Larger, prospective epidemiological multicenter studies will be needed to better determine the relationship between DM and periapical inflammation.

\section{REFERENCES}

1. Ajlouni K, Khader YS, Batieha A, Ajlouni H, El-Khateeb M. An increase in prevalence of diabetes mellitus in Jordan over 10 years. J Diabetes Complications 2008 Sep-Oct;22(5):317-324.

2. Soumya D, Srilatha B. Late stage complications of diabetes and insulin resistance. J Diabetes Metab 2011 Dec;2:167.

3. Salvi GE, Carollo-Bittel B, Lang NP. Effects of diabetes mellitus on periodontal and peri-implant conditions: update on associations and risks. J Clin Periodontol 2008 Sep;35 (Suppl 8):398-409.

4. Chávarry NG, Vettore MV, Sansone C, Sheiham A. The relationship between diabetes mellitus and destructive periodontal disease: a meta-analysis. Oral Health Prev Dent 2009 Feb;7(2):107-127.

5. Khader YS, Dauod AS, El-Qaderi SS, Alkafajei A, Batayha WQ. Periodontal status of diabetics compared with nondiabetics: a meta-analysis. J Diabetes Complications 2006 Jan-Feb;20(1):59-68.

6. Mealey BL, Ocampo GL. Diabetes mellitus and periodontal disease. Periodontology 20002007 Jun;44(1):127-153.

7. Tsai C, Hayes C, Taylor GW. Glycemic control of Type 2 diabetes and severe periodontal disease in the US adult population. Community Dent Oral Epidemiol 2002 Jun;30(3):182-192.

8. Siqueira, JF Jr. Microbiology of apical periodontitis. In: Pitt Ford T, editor. Essential endodontology. Oxford (UK): Blackwell; 2008. p. 135-139.

9. Lima SM, Grisi DC, Kogawa EM, Franco OL, Peixoto VC, Gonçalves-Júnior JF, Arruda MP, Rezende TM. Diabetes 
mellitus and inflammatory pulpal and periapical disease: a review. Int Endod J 2013 Aug;46(8):700-709.

10. Marotta PS, Fontes TV, Armada L, Lima KC, Rôças IN, Siqueira JF Jr. Type 2 diabetes mellitus and the prevalence of apical periodontitis and endodontic treatment in an adult Brazilian population. J Endod 2012 Mar;38(3):297-300.

11. Sánchez-Domínguez B, López-López J, Jané-Salas E, Castellanos-Cosano L, Velasco-Ortega E, Segura-Egea JJ. Glycated hemoglobin levels and prevalence of apical periodontitis in type 2 diabetic patients. J Endod 2015 May;41(5): 601-606.

12. American Diabetes Association. Standards of medical care in diabetes - 2012. Diabetes Care 2012 Jan;35(Suppl 1): S11-S63.

13. Orstavik D, Kerekes K, Eriksen HM. The periapical index: a scoring system for radiographic assessment of apical periodontitis. Endod Dent Traumatol 1986 Feb;2(1):20-34.

14. Green EA, Eynon EE, Flavell RA. Local expression of TNFalpha in neonatal NOD mice promotes diabetes by enhancing presentation of islet antigens. Immunity 1998 Nov;9(5):733-743.

15. Graves DT, Kayal RA. Diabetic complications and dysregulated innate immunity. Front Biosci 2008 Jan;13:1227-1239.

16. Fouad AF. Diabetes mellitus as a modulating factor of endodontic infections. J Dent Educ 2003 Apr;67(4):459-467.

17. Fouad A, Barry J, Russo J, Radolf J, Zhu Q. Periapical lesion progression with controlled microbial inoculation in a Type 1 diabetic mouse model. J Endod 2002 Jan;28(1):8-16.

18. Bender IB, Bender AB. Diabetes mellitus and the dental pulp. J Endod 2003 Jun;29(6):383-389.

19. Russell BG. The dental pulp in diabetes mellitus. Acta Pathol Microbiol Scand 1967 Sep;70(2):319-320.

20. Britto LR, Katz J, Guelmann M, Heft M. Periradicular radiographic assessment in diabetic and control individuals. Oral Surg Oral Med Oral Pathol Oral Radiol Endod 2003 Oct;96(4):449-452.

21. Fouad AF, Burleson J. The effect of diabetes mellitus on endodontic treatment outcome: data from an electronic patient record. J Am Dent Assoc 2003 Jan;134(1):43-51.

22. De Moor RJ, Hommez GM, De Boever JG, Delmé KI, Martens GE. Periapical health related to the quality of root canal treatment in a Belgian population. Int Endod J 2000 Mar;33(2):113-120.

23. De Cleen MJ, Schuurs AH, Wesselink PR, Wu MK. Periapical status and prevalence of endodontic treatment in an adult Dutch population. Int Endod J 1993 Mar;26(2):112-119.

24. Buckley M, Spångberg LS. The prevalence and technical quality of endodontic treatment in an American subpopulation. Oral Surg Oral Med Oral Pathol Oral Radiol Endod 1995 Jan;79(1):92-100.

25. Al-Omari MA, Hazaa A, Haddad F. Frequency and distribution of root filled teeth and apical periodontitis in a Jordanian subpopulation. Oral Surg Oral Med Oral Pathol Oral Radiol Endod 2011 Jan;111(1):e59-e65.

26. Hamasha AA, Sasa I, Al-Qudah M. Risk indicators associated with tooth loss in Jordanian adults. Community Dent Oral Epidemiol 2000 Feb;28(1):67-72.
27. Segura-Egea JJ, Jiménez-Pinzón A, Ríos-Santos JV, VelascoOrtega E, Cisneros-Cabello R, Poyato-Ferrera M. High prevalence of apical periodontitis amongst type 2 diabetic patients. Int Endod J 2005 Aug;38(8):564-569.

28. Doyle SL, Hodges JS, Pesun IJ, Baisden MK, Bowles WR. Factors affecting outcomes for single-tooth implants and endodontic restorations. J Endod 2007 Apr;33(4):399-402.

29. Mindiola MJ, Mickel AK, Sami C, Jones JJ, Lalumandier JA, Nelson SS. Endodontic treatment in an American Indian population: a 10-year retrospective study. J Endod 2006 Sep;32(9):828-832.

30. López-López J, Jané-Salas E, Estrugo-Devesa A, VelascoOrtega E, Martín-González J, Segura-Egea JJ. Periapical and endodontic status of Type 2 diabetic patients in Catalonia, Spain: a cross-sectional study. J Endod 2011 May;37(5):598-601.

31. Lupi-Pegurier L, Bertrand MF, Muller-Bolla M, Rocca JP, Bolla M. Periapical status, prevalence and quality of endodontic treatment in an adult French population. Int Endod J 2002 Aug;35(8):690-697.

32. Terças AG, de Oliveira AE, Lopes FF, Maia Filho EM. Radiographic study of the prevalence of apical periodontitis and endodontic treatment in the adult population of São Luís, MA, Brazil. J Appl Oral Sci 2006 Jun;14(3):183-187.

33. Gencoglu N, Pekiner FN, Gumru B, Helvacioglu D. Periapical status and quality of root fillings and coronal restorations in an adult Turkish subpopulation. Eur J Dent 2010 Jan;4(1):17-22.

34. Eriksen HM, Berset GP, Hansen BF, Bjertness E. Changes in endodontic status 1973-1993 among 35-year-olds in Oslo, Norway. Int Endod J 1995 May;28(3):129-132.

35. Weiger R, Hitzler S, Hermle G, Lost C. Periapical status, quality of root canal fillings and estimated endodontic treatment needs in an urban German population. Endod Dent Traumatol 1997 Apr;13(2):69-74.

36. Jiménez-Pinzón A, Segura-Egea JJ, Poyato-Ferrera M, VelascoOrtega E, Ríos-Santos JV. Prevalence of apical periodontitis and frequency of root-filled teeth in an adult Spanish population. Int Endod J 2004 Mar;37(3):167-173.

37. Armada-Dias L, Breda J, Provenzano JC, Breitenbach M, Rôças ID, Gahyva SMM, Siqueira JF Jr. Development of periradicular lesions in normal and diabetic rats. J Appl Oral Sci 2006 Sep-Oct;14(5):371-375.

38. Wray L. The diabetic patient and dental treatment: an update. Br Dent J 2011 Sep;211(5):209-215.

39. Ng YL, Mann V, Gulabivala K. A prospective study of the factors affecting outcomes of nonsurgical root canal treatment: Part 1: periapical health. Int Endod J 2011 Jul;44(7):583-609.

40. Ferreira M, Carrillo E, Carrilho F. Diabetes mellitus and its influence on the success of endodontic treatment: a retrospective clinical study. Acta Med Port 2014 Jan-Feb;27(1):15-22.

41. Grondahl HG, Huumonen S. Radiographic manifestations of periapical inflammatory lesions how new radiological techniques may improve endodontic diagnosis and treatment planning. Endod Top 2004 Jul;8(1):55-67.

42. Morgental RD, Santos RB, Rösing CK, Chanin Tdo A, Figueiredo JA. Interference of partial visual analysis of root filling quality and apical status on retreatment decisions. J Appl Oral Sci 2012 Mar-Apr;20(2):206-211. 